\title{
Erratum to: Hepatitis C Treatment in HIV Coinfection: Approaches, Challenges, and Future Opportunities
}

Autumn Bagwell, PharmD, BCPS ${ }^{1}$ Cody A. Chastain, $M D^{2, *}$

\section{Address}

${ }^{1}$ Department of Pharmacy, Vanderbilt Specialty Pharmacy, Vanderbilt University Medical Center, Nashville, TN, USA

*,2Division of Infectious Diseases, Vanderbilt University Medical Center, A2200 MCN, 1161 21st Avenue South, Nashville, TN, 37232-2605, USA

Email: cody.a.chastain@vanderbilt.edu

Published online: 28 November 2016

(C) Springer Science+Business Media New York 2016

The online version of the original article can be found under at http://dx.

doi.org/10.1007/s40506-016-0097-1.

\section{Erratum to: Curr Treat Options Infect Dis \\ DOI 10.1007/s40506-016-0097-1}

The original version of this article unfortunately contained a mistake. The alignment of entries in Table 1 was incorrect. On the second page of Table 1 (page 6/21), the columns for paritaprevir/ritonavir under NS3/4A Inhibitors are off.

The corrected Table 1 is given below. 


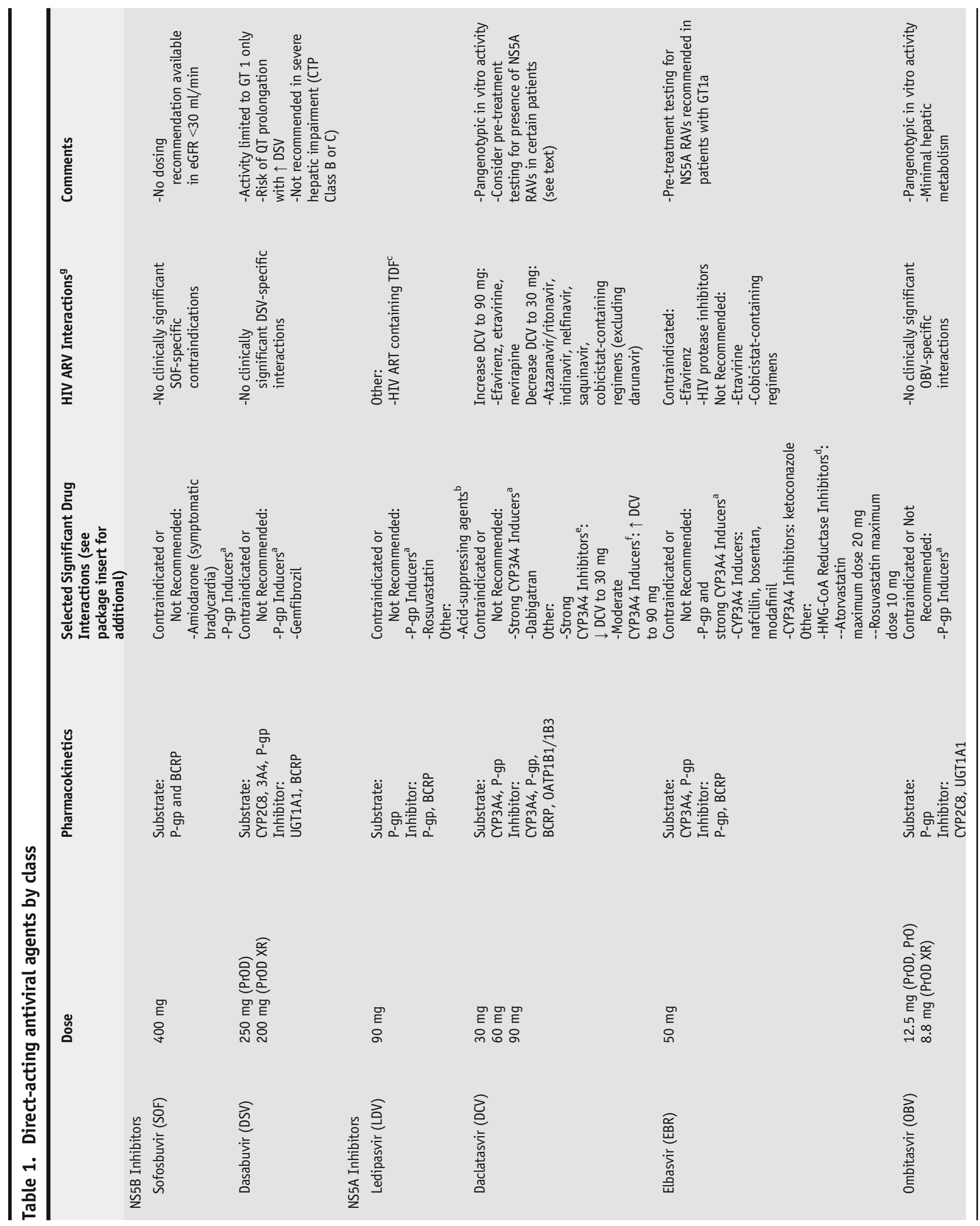


홍
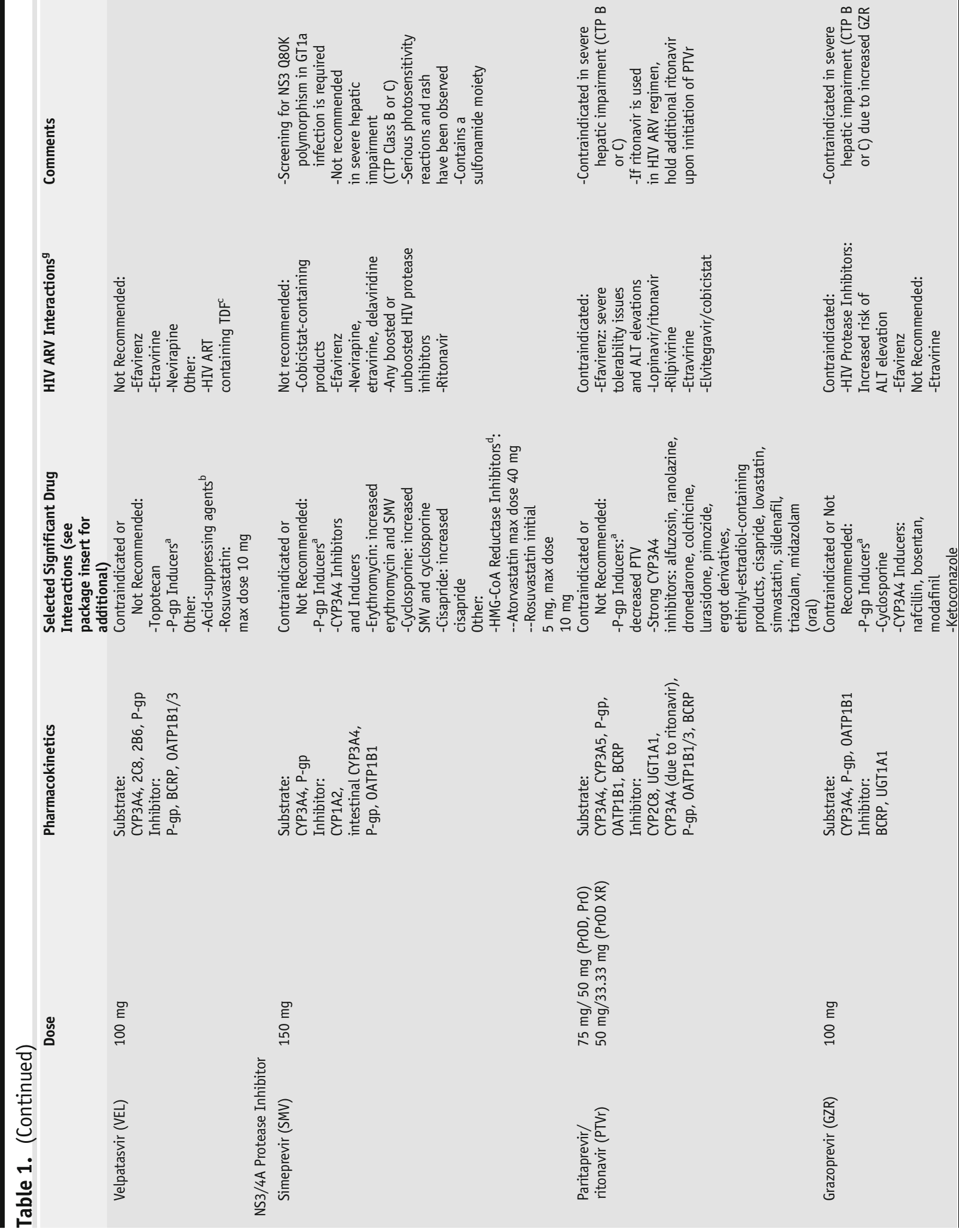


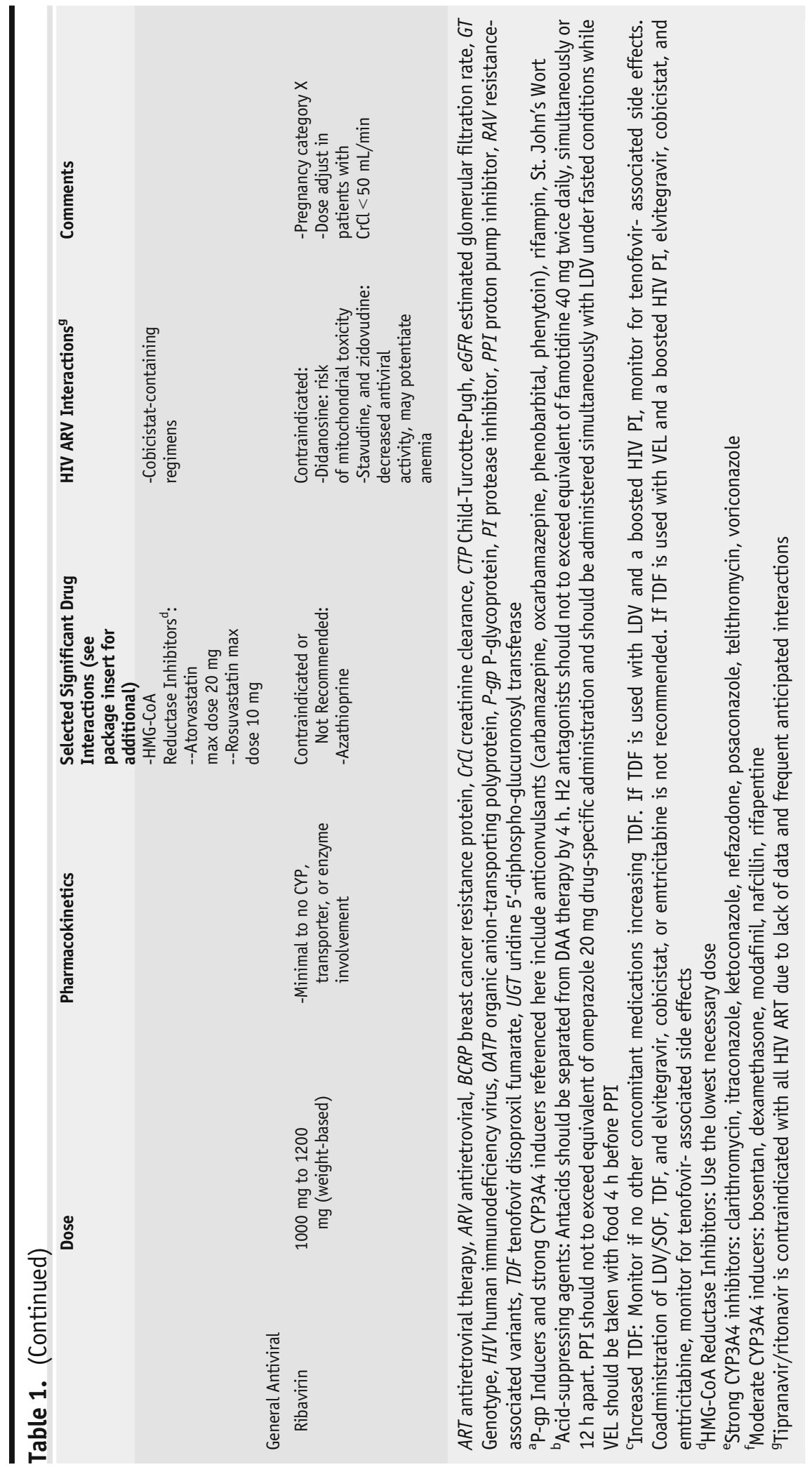

